\title{
Prevalence of congenital heart disease in black schoolchildren of Soweto, Johannesburg ${ }^{1}$
}

\author{
M. J. MCLAREN ${ }^{2}$, A. S. LACHMAN ${ }^{2}$, AND J. B. BARLOW \\ From the Cardiovascular Research Unit, Department of Medicine, University of the Witwatersrand and \\ the Cardiac Clinic, General Hospital, fohannesburg, South Africa
}

SUMMARY A survey conducted by cardiologists in Soweto, Johannesburg, provided an opportunity of assessing the frequency of congenital heart disease in black schoolchildren. Among 12050 schoolchildren aged 2 to 18 years, 48 had a congenital heart defect, yielding a prevalence of 3.9 per 1000 . Only in 2- to 6-year-old children did the prevalence exceed that of rheumatic heart disease. 'The distribution of the types of defects was largely similar to that reported in other surveys with a predominance $(52 \%)$ of ventricular septal defects. Two unusual findings were the unexplained absence of persistent ductus arteriosus in these children, and the detection of 5 children with situs inversus ( 1 in 2410). In all but one child, the congenital heart defect was first discovered during the survey. Despite the limitations of a prevalence study, it can be concluded that congenital heart disease is at least as common in this South African black community as in Caucasians.

The reported frequency of congenital heart disease in children is influenced by the standards of health care and availability of cardiac services to detect and treat such children. In Africa, where many infants are delivered at home and a large proportion of the population is served by unsophisticated rural health clinics, congenital heart disease has been said to be less common in black children than in white (Schwartz et al., 1958; Shaper and Williams, 1960). Several clinical and necropsy studies (Watler, 1960; Schrire, 1963, 1964; Van der Horst, 1965; Caddell and Connor, 1966; Caddell and Morton, 1967; Van der Horst et al., 1968) have suggested, however, that there is no difference in incidence among the 2 groups, but these studies included only those patients who came to the attention of physicians or cardiologists. In populations in which the seeking of modern medical care is not yet generally accepted, it is probable that many children either die before the heart defect

\footnotetext{
${ }^{1}$ Supported by South African Medical Research Council, Anglo American Corporation of South Africa Limited, South African Breweries Institute, and the Stella and Paul Loewenstein Cardiac Fund of the University of the Witwatersrand.

${ }^{2}$ Present address: Cardiology Unit, New Britain General Hospital, New Britain, Connecticut, USA.

Received for publication 11 September 1978
}

is detected or remain undiagnosed. Estimation of the prevalence of congenital heart disease in black schoolchildren provides some indication of the extent of the problem in a community and also of the frequency with which it is missed through childhood years. It does not reflect the true frequency of congenital heart disease as it does not take into account the large number of children who have died in infancy or early childhood (Campbell, 1973). The high case fatality rate during the neonatal period reduces the incidence from about 8 per 1000 (Landtman, 1965; Kerrebijn, 1966; Carlgren, 1969; Mitchell et al., 1971) at birth to a prevalence of 5 per 1000 at the end of the first year of life (Campbell, 1973) and others will die before reaching school age. Furthermore, many small ventricular septal defects may close spontaneously during the first few years and will not be detected in school surveys (Mitchell et al., 1967; Moss and Siassi, 1970). Prevalence studies on congenital heart disease in schoolchildren exclude retarded children in whom the prevalence of congenital heart disease is greater than in the general population (Doyle and Rutkowski, 1970). Despite these limitations it was still considered worth while to assess the prevalence of congenital heart disease during a survey on rheumatic heart disease (McLaren et al., 1975) in black schoolchildren of the South Western Townships of Johannesburg (Soweto). 


\section{Subjects and methods}

Details of the Soweto population and sampling technique have been previously described (McLaren et al., 1975). In 1972, a stratified random sample of 12050 children was drawn from a total Soweto school population of 99000 . An age range of 2 to 18 years was obtained and the age distribution was as follows: 2 to 6 years $(21 \%) ; 7$ to 10 years $(29 \%)$; 11 to 14 years (35\%); and 15 to 18 years ( $15 \%$ ). The number of boys and girls was equal.

The children were screened at the schools or crèches by a team of 10 doctors, 5 of whom were experienced cardiologists and the remainder of whom had all received at least 6 months training in this cardiac unit. Three observers, at least one of whom was a senior cardiologist, were present at each session. All children were examined initially by one observer, but if organic heart disease was suspected or detected the child was then 'recirculated' (McLaren et al., 1975) to the other 2 observers who were unaware that the child had been previously examined and 3 independent and unbiased assessments were thus obtained. At the end of each session such children were again examined by the 3 observers and all had to agree that organic heart disease was present before the final positive diagnosis could be accepted. Electrocardiograms and blood pressure examinations were performed on these children and they were referred to a cardiac clinic for chest radiographs and further management.

The relation of congenital heart disease to age, sex, educational level, and nutritional status was assessed. The practice of recirculation made possible a study of observer performance in the detection of congenital heart disease. The types of congenital heart defects are discussed but their numbers are too small to permit meaningful analysis of age and sex distribution. Statistical testing of associations was based on a $\chi^{2}$ test.

\section{Results}

Congenital heart defects were detected in 48 of the total of 12050 children. The optimally weighted estimate (Cochran, 1963) of the prevalence in the school population was 3.9 per 1000 with a 95 per cent confidence interval of $\pm 1 \cdot 2$. In all but one child, who had previously undergone surgery for closure of a ventricular septal defect, the diagnosis of congenital heart disease was made for the first time during the survey.

In crèche children aged 2 to 6 years, the prevalence was 2.95 per 1000 , whereas in lower primary (first 4 school years) and higher primary (fifth to eighth school years), it was 3.31 and 4.74 per 1000 , respec-

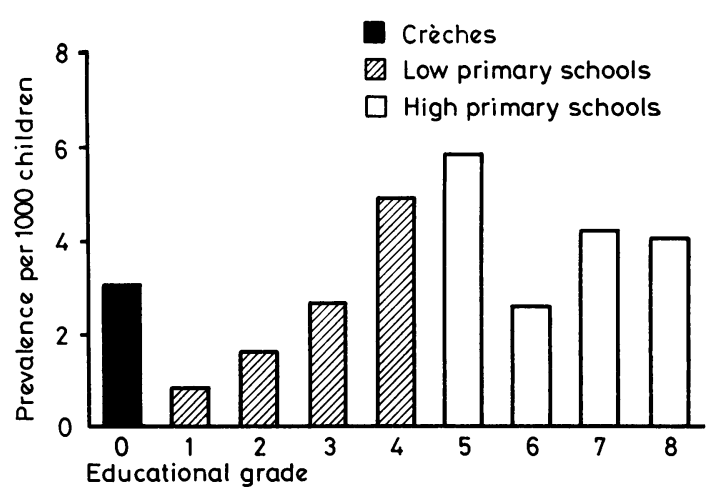

Fig. 1 Prevalence of congenital heart disease in Soweto children of different educational grades.

tively (Fig. 1). The observed increase in prevalence with educational grade was not significant at the 5 per cent level. Similarly, there was no significant relation of congenital heart disease with age but the prevalence was less than that of rheumatic heart disease in the children 7 years of age and older (Fig. 2). The ratio of the prevalence rate in boys to that in girls was $1 \cdot 42$. The nutritional status of children with congenital heart disease was assessed as normal in 76 per cent, overnourished in 7 per cent, and undernourished in 17 per cent, whereas in children with normal hearts it was 86 per cent, 7 per cent, and 7 per cent, respectively.

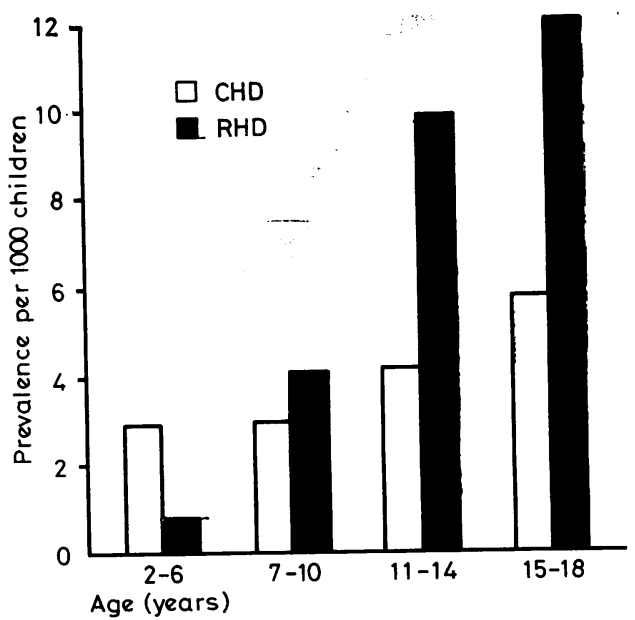

Fig. 2 Age specific prevalence rates of congenital (CHD) and rheumatic (RHD) heart disease in 12050 Soweto schoolchildren. The prevalence of CHD exceeds that of RHD in 2- to 6-year-old children only. 
Table 1 Prevalence and distribution of specific congenital heart defects in Soweto children

\begin{tabular}{lccc}
\hline Type & $\begin{array}{l}\text { No. of } \\
\text { children }\end{array}$ & $\begin{array}{l}\text { Prevalence } \\
\text { per 1000 }\end{array}$ & $\begin{array}{l}\text { Percentage } \\
\text { of total } \\
\text { congenital } \\
\text { heart defects }\end{array}$ \\
\hline Ventricular septal defect & 25 & $2 \cdot 07$ & $52 \cdot 1$ \\
Atrial septal defect & 5 & 0.42 & $10 \cdot 4$ \\
Dextrocardia & 5 & 0.42 & 10.4 \\
Bicuspid aortic valve & $2 \star$ & 0.17 & $4 \cdot 2$ \\
Pulmonary stenosis & 2 & 0.17 & $4 \cdot 2$ \\
Ebstein's anomaly & 1 & 0.08 & $2 \cdot 0$ \\
Isolated pulmonary & & 0.66 & 16.7 \\
$\quad$ regurgitation & 8 & 3.99 & 100.0 \\
Total & 48 & &
\end{tabular}

¿In one child, there was an associated coarctation of the aorta.

SPECIFIC CONGENITAL HEART DEFECTS

The distribution of individual congenital heart defects in the children is shown in Table 1.

\section{Ventricular septal defects}

Of the 25 children with ventricular septal defects, 9 were boys, 15 were girls, and the sex of the remaining child was not recorded. In 20 children, the lesions were classified as very small ventricular septal defects characterised by a so-called 'atypical' (Van der Hauwaert and Nadas, 1961; Vogelpoel et al., 1961; Barlow and Pocock, 1965) high pitched crescendo-decrescendo systolic murmur ending well before the second heart sound and heard best at the lower left sternal border. The remainder of the children with ventricular septal defects had pansystolic murmurs and the shunts were clinically assessed as small in 4 and moderate in 1.
Atrial septal defects

An ostium secundum defect was diagnosed in 4 children and an ostium primum defect in 1 child. In 2 of the children with ostium secundum defects, the shunt was assessed as moderate and both these children have since had surgical closure of these defects. In the remaining 3 children, the shunts were small.

\section{Dextrocardia with situs inversus}

Five children, 4 boys and 1 girl, had mirror-image dextrocardia with otherwise normal hearts. Vibratory systolic murmurs were present in 4 . These children were of varying ages $(5,7,10,14$, and 15 years) and from different geographical areas of Soweto.

\section{Bicuspid aortic valves}

The presence of a bicuspid aortic valve was suspected in 2 girls, aged 12 and 17 years. The 12-yearold girl had an ejection systolic murmur associated with an aortic ejection click. The 17-year-old had moderate aortic regurgitation but the additional signs of radio-femoral delay and hypotension in the lower extremities led to the diagnosis of an associated coarctation of the aorta.

\section{Pulmonary stenosis}

Pulmonary valvular stenosis was diagnosed in 2 girls, aged 11 and 15 years. In the latter child, the degree of stenosis was assessed clinically as moderate with a probable pressure difference across the pulmonary valve of about $40 \mathrm{mmHg}$.

Table 2 Prevalence of congenital heart disease in school surveys

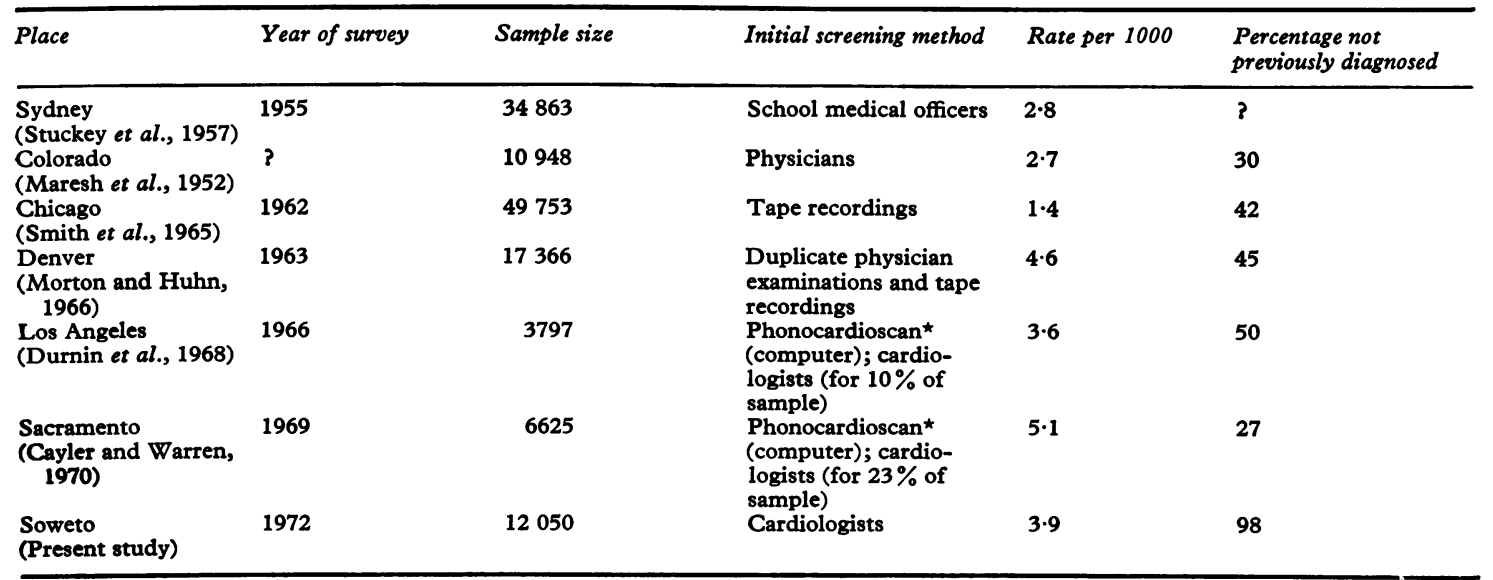

*Portable analogue-digital computer by which heart sounds are analysed on a beat-by-beat basis. 
Isolated pulmonary regurgitation

In 8 children, a short medium-pitched early diastolic murmur was present over the second left interspace and congenital mild pulmonary regurgitation was diagnosed (Baba et al., 1974).

\section{Ebstein's anomaly}

One child, a 13-year-old boy, had the typical clinical, electrocardiographic and radiological features of Ebstein's anomaly (Pocock et al., 1969).

\section{OBSERVER PERFORMANCE}

On recirculation of the 48 children in whom congenital heart disease had been detected by the first observer, the diagnosis was missed by one or both of the subsequent examiners in 11 children. Ventricular septal defects were missed in 5 children, an atrial septal defect in 1 child, dextrocardia in 2, and minor abnormalities of the pulmonary valve in 3.

\section{Discussion}

The prevalence of congenital heart disease in Soweto schoolchildren is in the upper part of the range of rates obtained in school surveys in other parts of the world (Table 2). However, caution is necessary when comparing rates in these studies because the methods of initial screening of the children differ. In some surveys, tape recordings (Smith et al., 1965), computers (Durnin et al., 1968; Cayler and Warren, 1970), or examinations by doctors with no specific training in cardiology were used though positive cases were later examined by cardiologists (Stuckey et al., 1957; Morton and Huhn, 1966). In the Soweto survey, cardiologists performed the initial screening and therefore the detection rate was probably relatively increased. The practice of recirculation and independent triplicate examinations for all children with abnormal hearts reduced the yield of false positives and also observer bias. In South Africa, the absence of compulsory schooling for black children tends to exclude from the sample those children with more severe forms of congenital heart disease who would be less likely to be attending school. The case fatality rate of congenital heart disease in the first few years of life is probably high in this population because of the common practice of home deliveries and the high general infant mortality. The prevalence rate in the Soweto school population may, therefore, be an underestimate of the true prevalence in this community. It can nevertheless be concluded that the prevalence is at least as common as in white schoolchildren.

The distribution of the types of congenital heart disease, with a predominance of ventricular septal defects (Maresh et al., 1952; Stuckey et al., 1957; Morton and Huhn, 1966; Cayler and Warren, 1970), is similar to that reported in other school surveys. There were two unusual findings. Firstly, despite impressions that persistent ductus arteriosus is more common at high altitudes such as Johannesburg which is 6000 feet above sea level (Alzamora et al., 1952; Bradlow et al., 1964), no child with this defect was detected. A possible reason for this is that children in this population with an unoperated large persistent ductus arteriosus may have a high morbidity and mortality caused by increased pulmonary infections and cardiac failure superimposed on a background of low socioeconomic status and malnutrition. This does not explain the absence of children with small defects or of those who had had operations for closure of larger defects. However, the total number of positive cases was only 48 and was thus too small to permit reliable estimates of the prevalence of individual defects and conclusions thereof. Secondly, though the reported prevalence of dextrocardia is only 1 per 22000 (Hollman, 1968), 5 children with this anomaly were detected in Soweto (1 per 2410) and all had situs inversus. The variation in age and geographical distribution did not suggest a clustering of cases with a common causation. Unfortunately it was not possible for us to obtain more detailed family histories. Again, this apparent high prevalence of situs inversus could represent a chance occurrence in a relatively small sample.

In contrast to other school studies (Table 2), the prevalence of previously undiagnosed congenital heart disease was high. The combined prevalence of previously undiagnosed congenital and rheumatic heart disease in Soweto schoolchildren was 9.37 per 1000 compared with a total prevalence of 10.8 per 1000. The large proportion of children with heart disease detected for the first time during this survey and the fact that rheumatic heart disease still exceeds the rate for congenital heart disease in all children over the age of 6 years are causes for concern about the availability and utilisation of quality health care for this community.

We are grateful to Drs K. R. Bloom, D. M. Bramwell-Jones, E. Cohen, G. E. Gale, K. Kanarek, J. B. Lakier, and W. A. Pocock for their help in the auscultation of the children. We thank Mr E. Rogat of the Epidemiology Branch, National Heart, Lung and Blood Institute, Bethesda, Maryland, for assistance with the statistical analysis. 


\section{References}

Alzamora, V., Rolta, A., Battilana, G., Abugattas, R., Rubio, G., Bouroncle, J., Zapata, C., Santa-Maria, E., Binder, T., Subiria, R., Paredes, D., Pando, B., and Graham, G. (1952). On the possible influence of great altitudes on the determination of certain cardiovascular anomalies. Pediatrics, 12, 259-262.

Baba, K., Tomita, Y., Yoshikawa, J., Tanaka, K., Hirashima, S., and Yoshizumi, M. (1974). Congenital isolated pulmonary valve insufficiency. Cardiovascular Sound Bulletin, 4, 445-455.

Barlow, J. B., and Pocock, W. A. (1965). The isolated systolic murmur. South African Medical fournal, 39, 909-918.

Bradlow, B. A., Zion, M. M., and Fleishman, S. J. (1964). Heart disease in Africa with part!cular reference to Southern Africa. American fournal of Cardiology, 13, 650-669.

Caddell, J. L., and Connor, D. H. (1966). Congenital heart disease in Ugandan children. British Heart fournal, 28, 766-767.

Caddell, J. L., and Morton, P. (1967). The pattern of congenital heart disease in Yoruba children of Western Nigeria. American Heart fournal, 73, 431.

Campbell, M. (1973). Incidence of cardiac malforniations at birth and later, and neonatal mortality. British Heart fournal, 35, 189-200.

Carlgren, L. E. (1969). The incidence of congenital heart disease in Gottenburg. Bulletin of the Association of European Paediatric Cardiologists, 5, 12.

Cayler, G. G., and Warren, M. G. (1970). Benefits from mass evaluation of schoolchildren for heart disease (experience with 6,625 children). Chest, 58, 349-351.

Cochran, W. G. (1963). Sampling Techniques. Wiley, New York.

Doyle, E. F., and Rutkowski, M. (1970). Etiology of congenital heart disease. Cardiovascular Clinics, 2, No. 1, $1-25$.

Durnin, R. E., Stanton, R. E., Gallaher, M. E., Golding, R. E., Gathman, G., and Fyler, D. C. (1968). Heart-sound screening in children. Fournal of the American Medical Association, 203, 1113-1118.

Hollman, A. (1968). Paediatric Cardiology. Lloyd-Luke, London.

Kerrebijn, K. F. (1966). Incidence in infants and mortality from congenital malformations of the circulatory systems. Acta Paediatrica Scandinavica, 55, 316-320.

Landtman, B. (1965). Epidemiological aspects of congenital heart disease. Acta Paediatrica Scandinavica, 54, 467-473.

McLaren, M. J., Hawkins, D. M., Koornhof, H. J., Bloom, K. R., Bramwell-Jones, D. M., Cohen, E., Kanarek, K., Lachman, A. S., Lakier, J. B., Pocock, W. A., and Barlow, J. B. (1975). Epidemiology of rheumatic heart disease in black schoolchildren of Soweto, Johannesburg. British Medical fournal, 3, 474-478.

Maresh, G. J., Dodge, H. J., and Lichty, J. A. (1952). Incidence of heart disease among Colorado school children. fournal of the American Medical Association, 149, 802-805.

Mitchell, S. C., Berendes, H., and Clark, W. M., jun (1967).
The normal closure of the ventricular septum. American Heart fournal, 73, 334-338.

Mitchell, S. C., Korones, S. B., and Berendes, H. W. (1971). Congenital heart disease in 56,109 births; incidence and natural history. Circulation, 43, 323-332.

Morton, W. E., and Huhn, L. A. (1966). Epidemiology of congenital heart disease, observations in 17,366 Denver school children. Fournal of the American Medical Association, 195, 1107-1110.

Moss, A. J., and Siassi, B. (1970). Natural history of ventricular septal defect. Cardiovascular Clinics, 2, No. 1, 140-154.

Pocock, W. A., Tucker, R. B. K., and Barlow, J. B. (1969). Mild Ebstein's anomaly. British Heart fournal, 31, 327-336.

Schrire, V. (1963). Experience with congenital heart disease at Groote Schuur Hospital, Cape Town. South African Medical fournal, 37, 1175-1180.

Schrire, V. (1964). The racial incidence of the less common forms of heart disease at Groote Schuur Hospital, Cape Town, 1952-1961. South African Medical fournal, 38, 598-601.

Schwartz, M. B., Schamroth, L., and Seftel, H. C. (1958). The pattern of heart disease in the urbanized (Johannesburg) African. Medical Proceedings, 4, 275-281.

Shaper, A. G., and Williams, A. W. (1960). Cardiovascular disorders at an African hospital in Uganda. Transactions of the Royal Society of Tropical Medicine and Hygiene, 54, 12-28.

Smith, J. M., Stamler, J., Miller, R. A., Paul, M. H., Abrams, I., Restivo, R. M., and DeBoer, L. (1965). Results of mass field trials with use of tape recorded heart sounds. III. The Chicago area high school study. Circulation, 32, 966-976.

Stuckey, D., Dowd, B., and Walsh, H. (1957). Cardiac murmurs in schoolchildren. Medical fournal of Australia, 1, 36-38.

Van der Hauwaert, L., and Nadas, A. S. (1961). Auscultatory findings in patients with a small ventricular septal defect. Circulation, 23, 886-891.

Van der Horst, R. L. (1965). The management of serious heart disease in the neonate and infant. South African Medical fournal, 39, 786-791.

Van der Horst, R. L., Winship, W. S., Pittaway, D., Gibb, B. H., and Lapinsky, G. B. (1968). Congenital heart disease in the South African Bantu: a report of 117 cases. South African Medical fournal, 42, 1271-1273.

Vogelpoel, L., Schrire, V., Beck, W., Nellen, M., and Swanepoel, A. (1961). The atypical systolic murmur of minute ventricular septal defect and its recognition by amyl nitrite and phenylephrine. American Heart fournal, 62, 101-118.

Watler, D. C. (1960). Congenital heart disease in Jamaica. West Indian Medical fournal, 9, 194-200.

Requests for reprints to Professor J. B. Barlow, Cardiac Unit, Department of Medicine, Witwatersrand University, Johannesburg, Republic of South Africa. 